\title{
La reivindicación de un "diccionario gallego" en el siglo XIX*
}

\author{
XOÁN GONZÁLEZ-MILLÁN \\ Hunter College/Graduate Center. \\ CUNY. Nueva York
}

\section{RESUMEN}

La elaboración y publicación de un diccionario de la lengua gallega en la segunda mitad del siglo XIX es una reivindicación en la que se dan cita, por los múltiples intereses que en ella convergen, los diferentes elementos que constituyen el horizonte ideológico del movimiento "rexurdimentista" iniciado en la década de 1850. Para entender este proceso de demanda lexicográfica, es inevitable enmarcarlo en el clima sociocultural "provincialista" y "regionalista" que experimenta la Galicia de la época. La articulación de una renovada "identidad gallega", traducida fundamentalmente en términos filológicos, y el reconocimiento de que la producción impresa en gallego era un signo inequívoco del grado de vitalidad de esta identidad, representan dos aspectos claves de este movimiento que veía en el "Diccionario" la condición de instrumento ideal para articular una conciencia colectiva y para salvaguardar la lengua que le servía de referente.

Palabras clave: Diccionarios, Lexicografía gallega, "Rexurdimento".

\section{SUMMARY}

In the vindication of a Galician dictionary in the second half of the 19th Century coalesced the main currents of the "Rexurdimento" movement initiated around 1850, in connection with the multiple interests to which this movement tried to respond. Only in the context of the "provincialist" and "regionalist" ideologies articulated by the Galician intelligentsia of the time is feasible to understand this demand for lexicographical compendia. The philological framing of a "Galician identity", and the recognition that publishing

* Este artículo se publica de forma póstuma. El texto fue enviado a la redacción de la Revista por el Dr. Xoán González-Millán, quien al poco tiempo falleció de forma trágica junto a su mujer, en un accidente en el estado de Nueva York (EE.UU.). A requerimiento de la revista, el profesor Giuseppe Di Scipio, jefe del Departamento de Lenguas Románicas del Hunter College (CUNY), y Alejandro Alonso Nogueira, uno de los estudiantes de doctorado del profesor González-Millán, decidieron encargarse del trabajo de edición del artículo en memoria de su compañero y amigo. Agradecemos a ambos su amabilidad hacia nosotros y alabamos su intención de rendir homenaje a su colega, aunque sea de esta forma modesta (N. de la R.).

RDTP, LVIII, 2 (2003): 5-32 
in Galician was the most unequivocal sign of its vitality, represent two key elements of the lexicographical movement that saw in the "Dictionary" an ideal instrument to secure the future of the Galician language and to legitimize a related collective identity.

Key words: Dictionaries. Galician lexicography. "Rexurdimento".

\section{REPERTORIOS LEXICOGRÁFICOS}

Los diccionarios gallegos propiamente dichos hacen su aparición a partir de 1863 con la publicación póstuma del Diccionario gallego-castellano de Francisco J. Rodríguez, el primer proyecto lexicográfico que es publicado como tal "diccionario". Le seguirían el Diccionario gallego de Juan Cuveiro Piñol (1876) y el Diccionario gallego-castellano de Marcial Valladares (1884). Si la obra de Cuveiro había sido elaborada probablemente, como confiesa en una nota "Al lector", en los años sesenta, M. Valladares, de fiarnos de sus propias declaraciones, inicia su trabajo de recolección alrededor de 1850. Pero la actividad lexicográfica gallega no se limita a estos tres títulos. Hay que añadir el inconcluso Breve diccionario gallego (1853) de J. M. Pintos", el "Catálogo y significación de las voces del sub-dialecto berciano" incorporado a los Ensayos poéticos en dialecto berciano (1861) de A. Fernández y Morales, el "Glosario" elaborado por "M[anuel]. M[urguía]." como apéndice de los Cantares gallegos (1863) de Rosalía de Castro, el "Vocabulario de nombres y verbos gallegos con su equivalencia castellana" de F. Mirás, publicado como parte de su Compendio de gramática gallega-castellana (1864) y El habla gallega (1868) del ya citado Juan Cuveiro Piñol.

Un capítulo importante es el representado por los varios diccionarios y vocabularios que por diferentes razones quedaron inéditos, como muchos otros manuscritos de la Galicia decimonónica. Es el caso de los repertorios lexicográficos de B. V. Paizal, M. Leiras Pulpeiro, M. Murguía, J. M. Pintos, E. Pondal y F. Porto Rey, que en su momento pasarían a los fondos de la Real Academia Gallega y serían utilizados en la confección del primer diccionario de esta institución a principios del siglo xx. Habría que señalar otros dos proyectos lexicográficos de la década de 1860: el primero fue un "Diccionario del dialecto gallego", de Luis Aguirre del Río, del que se publicó una

\footnotetext{
${ }^{1}$ La nobleza de origen que Pintos reivindica sistemáticamente para el gallego queda recogida también en un corto vocabulario gallego-latino que incluye en A gaita gallega (1853), y que, como señala C. Hermida (1992a), puede ser considerado el primer intento de elaboración de un diccionario etimológico del gallego. Este dato es especialmente significativo en el contexto del "Pre-Rexurdimento" gallego porque, como sugieren Jean y Claude Dubois, "la présence de l'étymologie dans les dictionnaires depuis le XIX ${ }^{e}$ siècle relève non de considérations scientifiques, mais de nécessités de l'énoncé pédagogique et de la destination culturelle du dictionnaire" (1971: 108).
} 
entrega en el diario madrileño El Alba Católica, probablemente entre 1862 y 1863; también en Madrid se publicaron en 1868 los dos primeros fascículos de una "Gramática y Vocabulario del Dialecto Gallego", de Ramón Álvarez de la Braña, obra de la que, según C. Hermida, sólo se conoce la introducción (1992a: 73) ${ }^{2}$.

Un dato que debió de tener una especial incidencia en la elaboración de las compilaciones lexicográficas (vocabularios y diccionarios) en las primeras décadas del "Rexurdimento" (1850-1875) fue la decisión curricular tomada por la Escuela Superior de Diplomática de incluir el gallego como materia de estudio en $1861^{3}$. Las conexiones entre el estudio del gallego y sus posibles aplicaciones "diplomáticas" son detectables en varios textos de la época. Valga como ejemplo el prólogo al diccionario de Francisco J. Rodríguez en el que señala Antonio de la Iglesia: "El poeta, el numismático, el arqueólogo, el novelista, el anticuario, el historiador, el cursante de la escuela diplomática y el literato en fin, han menester del conocimiento del habla de los cantares de Alfonso X y de Macías, si en escritos ó de palabra se ocupan una vez de Galicia" (1863: VI-VII). En términos muy semejantes ya se había expresado este mismo prologuista en la "Memoria" que como secretario de los Juegos Florales de A Coruña de 1861 incorporó al Álbum de la Caridad (1862), una publicación en la que no sólo se recogían los textos premiados en este certamen literario sino también la primera gran antología poética

\footnotetext{
${ }^{2}$ Se conserva un extenso anuncio publicitario de esta última obra, aparecido en $E l$ Madrileño, en el que se señalan las características del proyecto: una publicación de unas " 25 entregas, en 8 o español de á 16 páginas cada una; papel y impresión de lo más selecto". En esta misma nota se alude también al diccionario de Aguirre: "Ya el ilustrado joven D. Luis Aguirre del Rio trata de subsanar en parte esta falta, dando á luz un copioso 'Diccionario'". Ver Hermida (1992a: 73-74) para más información sobre estos dos proyectos lexicográficos frustrados.

${ }^{3}$ Existía un precedente interesante sobre la utilidad del conocimiento del gallego para descifrar textos castellanos antiguos. En sus reflexiones sobre la "Idea de un diccionario de la lengua gallega", redactadas entre 1794 y 1797, el erudito benedictino Juan Sobreira ya comentaba: "[el] diccionario [de nuestra lengua gallega] sólo parece inútil a los que no la comprenden. No puedo ni debo creer que parezca tan mal a nuestros españoles diplomáticos, ni a todos aquellos que leen la historia para instrucción y no por diversión. Estos viven persuadidos de que muchísimos vocablos antiguos, vertidos en públicos instrumentos, sólo pueden ser entendidos por un gallego dedicado a la comprensión de su nativo idioma; y, con efecto, yo mismo, que toda mi vida sacrifiqué al estudio diplomático, salí, a beneficio de mi patrio idioma, de muchos pantanos en que se atollaron ingenios muy gigantes" (1974: 188-89). J. Sobreira, junto con el otro gran erudito benedictino del siglo XVIII M. Sarmiento, son piedras angulares en el esfuerzo de los provincialistas y regionalistas por rebatir el argumento (frecuentemente utilizado en la segunda mitad del siglo xIx) de que el gallego no podía ser calificado de "idioma" por carecer de gramática y diccionario.
} 
gallega del "Rexurdimento" cultural. Todavía en el año 1886, en su antología de textos gallegos $\mathrm{El}$ idioma gallego, tendrá una mención para los tres diccionarios entonces existentes, que considera entre los títulos más significativos del "Rexurdimento".

También el Diccionario gallego de Cuveiro Piñol llevaba un subtítulo revelador: "El más completo en términos y acepciones de todo lo publicado hasta el día con las voces antiguas que figuran en códices, escrituras y documentos antiguos, términos familiares y vulgares y su pronunciación, para la Escuela de Diplomática, anticuarios, jueces, abogados, escribanos, párrocos y otras personas a quienes es indispensable su frecuente uso". En un anuncio publicitario de este mismo diccionario, en el que se repite la información del subtítulo señalado, se añade un "prospecto", en el que se indica: "El libro que hemos anunciado al dar á luz el folleto titulado El habla gallega, se hace sentir cada día más su publicación, ya porque en la Escuela de Diplomática no se halla señalado de texto ni hay ninguno de esta índole [...]". No sería infrecuente encontrar en la década de los setenta y ochenta referencias a este reconocimiento de la Escuela de Diplomática, que significaba, a los ojos de los regionalistas gallegos, una valiosa aportación de capital simbólico a una lengua (y a una cultura) en desesperada necesidad de él.

La segunda mitad del siglo XIX muestra, pues, una notable actividad lexicográfica, si bien es claramente deficiente y está pobremente articulada, en parte porque en su elaboración fueron utilizados unos criterios que distaban de los avances epistémicos y analíticos que en aquellas décadas formaban parte del discurso lexicográfico europeo y los estudios filológicos en general. En combinaciones de diferente gradación, y con notables cambios de enfoque e interés a medida que avanzaban los años, las compilaciones lexicográficas gallegas repertoriadas en la primera época del "Rexurdimento" comparten un doble objetivo: en primer lugar, una preocupación por contribuir al entusiasmo científico representado por los estudios filológicos de la época; en segundo lugar, un intento por facilitar un "encuentro" lexicográfico entre el gallego y la lengua "oficial" del Estado, entendido siempre en términos de una legitimación político-simbólica muy desigual, ya que se partía de una visión dialectal del primeró.

\footnotetext{
${ }^{4}$ Son reveladores, en este sentido, los siguientes fragmentos extraídos del discurso de entrada de Francisco de Paula Canalejas en la Real Academia Española: "La renovación dialectal es uno de los medios más eficaces para la conservación y el desarrollo de los idiomas. Creo que la influencia que los dialectos ejercen en la lengua nacional en los diversos períodos de su historia, contribuye enérgicamente a mantener la vida y la frescura y a dotar de flexibilidad y de precisión a los idiomas. En la historia del castellano no sería difícil determinar las épocas de influencia andaluza o gallega, asturiana o aragonesa, no sólo en las cualidades poéticas, sino en las condiciones sintáxicas
} 
Como se observa en los siguientes versos del "pre-rexurdimentista" Juan Manuel Pintos incluidos en $A$ gaita gallega, la carencia de una gramática o un diccionario todavía son considerados en los años cincuenta un mal menor; mucho más urgente parecía entonces el incremento de la producción escrita en gallego, que en aquella época era mínima:

\author{
Ah de Dios, dicen alguns, \\ Que gramatica non temos \\ Nin diccionario tampouco \\ De significados cheo! \\ Má barredeira vos barra \\ Fato de parvos é lerdos! \\ Que gramatica estudiaron \\ Moises nin tampouco Homero? \\ E non fono os escritores \\ Millores do mundo inteiro? \\ Escriban tod'os que saben \\ O noso idioma gallego; \\ Fáganse dimpois apuntes \\ O millor sempre escollendo; \\ Redondeese o linguage \\ Como tod'os mais fixeron, \\ Que gramaticas dimpois \\ E diccionarios a centos \\ Veredes po los mercados \\ E nas tendas dos libreiros (Pintos 1853: 37-38)
}

\begin{abstract}
y lexiológicas que han permitido adquieran carta de naturaleza, formas provinciales y modismos locales" (Canalejas 1870: 51). El autor abunda en la misma idea un poco más adelante, en unos términos que reflejan inequívocamente una política lingüística nacional-estatal representada por la "gramática de la nación": "La renovación dialectal se cumple continua e incesantemente. Su fonética, su lexicología, su sintaxis, su prosodia, se rejuvenecen por un comercio constante con los dialectos, que mantienen la variedad lingüística dentro de la unidad nacional, y, por tanto, con las espontáneas creaciones de la vida que expresan esos dialectos propios, no sólo de una comarca, sino también de una generación; porque, en efecto, cada generación recibe de sus ideas, de sus dolores o de sus esperanzas formas peculiares, sello especial, que quedan en la lengua patria y que se perpetúan, cuando responden y concuerdan con el tipo general y con la fisonomía de la gramática de la nación" (Ibid.: 52). Este mismo marco explica que la reivindicación o el elogio de un determinado proyecto lexicográfico gallego a veces se vean apoyados por la desigual autoridad simbólica del castellano y del gallego, como se puede concluir de la siguiente nota anónima extraída de la publicación pontevedresa El Buscapié: "Cuando carece aun la lengua castellana de un diccionario de provincialismos, como carece de otro de sinónimos, no tendrá importancia un estudio [como El habla gallega de J. Cuveiro] que tanto puede contribuir á que aquellas obras se emprendan?" (93 [8.2.1868]).
\end{abstract}


Con todo, se pueden documentar ya en los años cincuenta y sesenta algunas declaraciones en las que se detecta una velada intencionalidad protonormativa, como se refleja en la nota editorial que precede a la publicación en 1849 del texto fundacional de la literatura dramática gallega, $A$ Casamenteira de A. B. Fandiño: "Como nuestro gallego no tiene según debiera arregladas una ortografía y una prosodia peculiares, resultando de aquí la gran variedad en escribirle, faltando muchas veces á la propiedad, alterando otras el significado de las voces y dejando la pronunciación sin reglas fijas al arbitrio del que lee" (Fandiño 2000: 112).

Pero será José Antonio Saco y Arce, privilegiado observador del desarrollo sociolingüístico gallego de mediados del XIX, quien sintetice en el "Prólogo" a su Gramática gallega (1868) algunas de las ideas generales que circulaban por los circuitos "provincialistas": sobre todo la imagen del gallego como un idioma carente de la fijación necesaria para funcionar con efectividad como instrumento de comunicación, fundamentalmente por escrito; la causa de esta situación la ve en la falta de una gramática y de un diccionario, pero también en la carencia de un canon de escritores "que con pluma magistral hayan manejado la lengua" (Saco 1868: X). Sin declararlo abiertamente, Saco parece reconocer en los factores señalados una cadena de causalidades mutuas: las grandes obras en gallego no serán publicadas en tanto no se "fije" la lengua, pero, simultáneamente, no se iniciarán estudios gramaticales ni lexicográficos si no existe un corpus literario que legitime y cargue de capital simbólico el sistema lingüístico en cuestión. En estas observaciones Saco y Arce se estaba anticipando a la imagen del "Diccionario" como un instrumento de normativización, una idea que será prevalente en las décadas siguientes.

En un artículo seriado, publicado diez años después en El Heraldo Gallego sobre los defectos más frecuentes en la poesía gallega contemporánea, el mismo Saco y Arce se lamentaba de la galopante invasión de "vocablos castellanos, con que inconsideradamente se mina la pureza del lenguaje" (5.1.1876 y en Hermida 1992b: 105-114); como remedio recomendaba un verdadero diccionario bilingüe: "que por una parte contenga el catálogo de nuestras voces verdaderamente castizas con su equivalencia castellana, y por otra la correspondencia gallega de todas las voces del idioma de Castilla" (Ibid.). La propuesta era tan revolucionaria para su tiempo que habría que aguardar casi un siglo para que una articulación lexicográfica semejante (gallego/castellano y castellano/gallego) se concretase en un mismo proyecto lexemático 5 . El gramático gallego sugería (y defendía) con su recomendación una inusitada igualdad de estatuto sociolingüístico entre ambos idiomas y anunciaba una

\footnotetext{
${ }^{5}$ En 1968 la editorial Galaxia lanza un Diccionario galego-castelán e Vocabulario castelán-galego, preparado por el poeta X. L. Franco Grande.
} 
nueva época para la lexicografía gallega, presidida por el explícito deseo de reivindicar y legitimar una cultura endógena que tenía como vehículo una lengua silenciada y desprestigiada desde el siglo Xv; es este un proyecto en el que la elaboración del "Diccionario gallego" va a centrar muchos de los esfuerzos individuales y colectivos por constituir un modelo normativo con capacidad institucional, en claro contraste con las propuestas sociolingüísticas de las décadas anteriores.

\section{MANUEL MURGUÍA}

En un trabajo serializado, titulado "Poesía gallega contemporánea", y publicado en la revista madrileña El Museo Universal, M. Murguía lamentaba ya en 1858 la carencia de un "mal diccionario" gallego, dadas las ventajas que podrían derivarse de tal instrumento de referencia:

Parece imposible, pero es la verdad, que de un dialecto, tan dulce, tan rico en armonía y voces, no exista no decimos, gramática, sino un mal diccionario que pudiese suplir aun cuando fuese de un modo imperfecto, á los viajes, á los estudios hechos con pérdida de tiempo, á que tiene que entregarse toda persona amante de nuestra lengua provincial, pues nada más cierto que esta varía á cada paso, como los trajes, como las costumbres de una á otra comarca. (4[28.2.1858] y en Hermida 1992b: 39).

En este diccionario básico tendría que quedar recogida, según Murguía, la amplia variabilidad comarcal del gallego, facilitando así el conocimiento de este "dialecto" a todos aquellos (fundamentalmente urbanitas castellanoparlantes) interesados en un más efectivo acceso a la cultura etnográfica gallega, cuya representación es formulada aquí en términos esencialmente ruralistas ${ }^{6}$. Esta misma idea de vitalidad y dinamismo lexemático la recogería el mismo autor unos años más tarde en el primer tomo de su Historia de Galicia:

Por no haber sido fijada en modelos literarios, varía de unas comarcas á otras [...] dando así lugar á una porción de dialectos, y por lo mismo, enriqueciendo el caudal de voces que es grande, distintivo de las lenguas usadas, por los campesinos [...]. Así lo que debía ser su muerte, vino á tornarse en fecundo venero, de donde el gallego saca la gran riqueza de su diccionario (1865: 326-327) ${ }^{7}$.

\footnotetext{
${ }^{6}$ No debería ser ajena a M. Murguía, cuando redactaba estas líneas en 1858, la imagen de los vocabularios multilingües utilizados profusamente desde el siglo XVI como instrumentos de gran utilidad para viajeros y comerciantes.

7 No es difícil percibir en esta reivindicación de la variabilidad dialectal los argumentos que Max Müller había presentado en sus Lectures on the Science of Language en la Royal Institution of Great Britain en 1861 y 1863, aunque el mismo Murguía se
} 
La recopilación de un diccionario gallego tendría, pues, como objetivo prioritario en estos momentos iniciales facilitar el acceso a un mundo cultural excesivamente fragmentado y desarticulado; y serviría, por tanto, como descodificador de una realidad sociolingüística "extraña", incluso para la misma intelectualidad galleguista de la época. La preocupación normativa, que se hará cada vez más patente en los proyectos lexicográficos posteriores, sobre todo a partir de la década de los ochenta, como quedó señalado más arriba, aún está ausente en esta fase de despegue del discurso lexicográfico gallego, a pesar de la alusión a la inexistencia de una gramática en el mismo párrafo citado, que permite intuir una implícita vocación proto-normativizadora.

En otra sección del primer volumen de su Historia de Galicia lamentaría también Murguía la inexistencia de un "diccionario especial" y de una gramática, y señalaría las negativas consecuencias que de esta deficiencia se derivaban para el estudio del gallego: "No habiéndose publicado todavía ningún estudio formal acerca del gallego, careciendo todavía de gramática y diccionario especial, se comprende desde luego, lo difícil que debe ser [...] estudiar nuestro idioma en toda su extensión, y con aquella suma de datos que necesita el que haya de tratar tal asunto á la manera que hoy se requiere" (Murguía 1865: 303). Llama la atención inmediatamente en esta evaluación de conjunto la insistencia en una aproximación analítica, "formal", según los nuevos criterios epistémicos que los estudiosos del fenómeno lingüístico, entre ellos los dedicados al análisis de los dialectos, estaban utilizando desde mediados del siglo XIX; pero al mismo tiempo, en estas mismas líneas Murguía, y como él otros "provincialistas" coetáneos, subraya ya un aspecto novedoso y de especial trascendencia: la legitimidad del gallego para ser considerado objeto de estudio y analizado como un fenómeno sociolingüístico específico ${ }^{8}$.

Probablemente consciente de las objeciones que los lectores familiariza-

encargase de distanciarse de él explícitamente unas líneas más arriba, citando la traducción francesa del primer volumen de las conferencias, publicado en París en 1864. Sobre la vitalidad de los "dialectos", y con un optimismo muy de la época, afirmaba el orientalista alemán: "Es casi imposible formarse una idea de la inagotable fecundidad de los dialectos: allí donde las lenguas literarias han estereotipado un término general, sus dialectos nos ofrecen cincuenta, cada uno con un matiz de significación. Si a consecuencia de los progresos de la sociedad nacen y se desarrollan nuevas ideas, los dialectos suministran inmediatamente los términos necesarios recurriendo a sus tesoros de palabras, a esos tesoros que pasan por inútiles" (Müller 1944: 76).

${ }^{8}$ En este mismo contexto, Carme Hermida, estudiosa del período, le concede una justificada relevancia a la Historia de Galicia (1849) de Martínez Padín y a la ya citada obra de J. M. Pintos, A gaita gallega, porque en ambas "a concesión dun apartado específico [al ámbito de la lengua] revelaba unha maior sensibilización cara ó tema e, de feito, supuxo o inicio do camiño ascendente que, a partir deste momento, seguiría o seu cultivo e a súa reivindicación" (1992a: 66). 
dos con el incipiente trabajo lexicográfico que en aquellos momentos se estaba desarrollando en Galicia podrían argüir, Murguía se ve obligado a añadir al texto citado una nota a pie de página en la que reconoce la existencia de los dos proyectos lexicográficos ya publicados en aquellos momentos, pero sometiéndolos a una categórica descalificación: "No creemos que puedan llamarse tales [diccionarios], los desgraciados libros, que, por equivocación sin duda, corren impresos con semejantes títulos. Cada día se hace más necesario, un profundo estudio de nuestro idioma, y como primer paso hacia él, la publicación de una gramática y diccionario gallego" (Ibid: 303, nota) $)^{9}$. Los compendios lexicográficos (implícitamente) aludidos no podían ser otros que el Diccionario gallego-castellano (1863) de F. Rodríguez y el "Vocabulario" de F. Mirás publicado como apéndice de su Compendio de gramática castellana-gallega (1864). No deja de ser paradójica esta negativa evaluación, sobre todo la del diccionario de F. Rodríguez, porque en el "Glosario" que el mismo M. Murguía preparó para Cantares gallegos (1863), el primer poemario gallego de Rosalía de Castro, su esposa, cita y utiliza ese mismo diccionario ${ }^{10}$.

Convendría añadir que el tono de retórica incredulidad con el que se manifestaba Murguía en las páginas de El Museo Universal ("Parece imposible") probablemente tenga su explicación en el repertorio de diccionarios con que otras lenguas periféricas del Estado, sobre todo las del área de influencia del catalán, contaban ya a mediados del siglo XIX. En la misma nota a pie de página arriba citada, hace suyas las palabras que Mariano Cubí y Soler había escrito para su introducción a Ensayos poéticos en dialecto berciano (1861) de Fernández y Morales: "No sé por qué ha de ser menos Galicia, que Valencia, Cataluña y hasta las Islas Baleares" (Ibid: 303, nota). Esta misma queja trasluce una nota publicitaria en la que el periódico El Madrileño anunciaba una "Gramática y vocabulario del dialecto gallego" de Ramón Álvarez de la Braña, escrita probablemente por el mismo autor, en la que se subrayaba el atraso filológico del gallego en comparación con los otros "dialectos" del Estado: "Últimamente, era extraño, que, de casi todos los [dialectos] que se hablan en España, se hubiesen hecho sus correspondientes gramáticas y diccionarios, y no así del suavísimo lenguage gallego"11.

\footnotetext{
9 Énfasis añadido.

${ }^{10}$ Las palabras de Murguía debieron de tener eco en los medios provincialistas de la época, si tenemos en cuenta la siguiente observación de J. Cuveiro Piñol en $E l$ habla gallega: "El Sr. D. Manuel Murguía en su Historia de Galicia, ha suscitado el celo de nuestros paisanos para la formación de una Gramática y un Diccionario" (1868: 83).

${ }^{11}$ Una copia de este anuncio se conserva en la colección de documentos del Fondo Casal y Lois del Museo de Pontevedra, con la sigla IV-17.
} 


\section{DICCIONARIOS E INSTITUCIONES}

Que la elaboración de un diccionario iba más allá del trabajo individual y requería de un esfuerzo mancomunado y de la intervención (económica e institucional) de los poderes públicos, representados fundamentalmente por las cuatro Diputaciones provinciales, es una idea que se detecta ya desde los momentos iniciales del "Rexurdimento". En el marco de su patriótica $A$ gaita gallega el poeta y erudito Juan Manuel Pintos es uno de los primeros en lanzar la idea de una junta de expertos, representativa de las diversas variantes dialectales, para recopilar el corpus lexicográfico gallego:

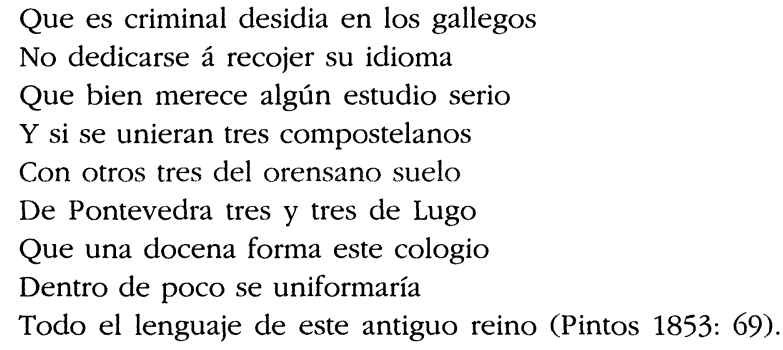

Unos versos en los que el autor se hace eco, con toda seguridad, de una idea esbozada en el siglo anterior por el benedictino Martín Sarmiento, quien en su Onomástico Etimológico de la Lengua Gallega, redactado entre 1757 y 1769 , mencionaba la posibilidad de una "Academia" constituida también por una docena de sabios ("aletho-philos" o "Veritatis Amatores"), aunque no sin un cierto grado de escepticismo: "No me opongo a que en Galicia haya una docena de 'Alethophilos' esparcidos, o que unidos en alguna parte como en 'Academia', trabajen sobre unos mismos principios, y al mismo fin. Es verdad que no estoy bien con esto de que muchos entendimientos se alisten en una "cofradía"' (Sarmiento 1998: 198-99).

En una especie de proto-prólogo que Marcial Valladares habría redactado alrededor de 1868 para su diccionario también se señala la necesidad de un trabajo colectivo y se reclama el apoyo económico de las Diputaciones:

Ante el movimiento material é intelectual de nuestra época, comprendemos la utilidad ahora como nunca de un completo 'Diccionario gallego-castellano', comprendemos no menos la casi imposibilidad de llevar á cabo tamaña empresa, á no mediar el concurso de las cuatro provincias gallegas, concurso fácil si sus Diputaciones entre sí quisieran entenderse y ofrecer digno premio cada una al mejor que en la suya respectiva se presentase. Tendríamos entonces diccionarios parciales de todas ellas, materiales suficientes acopiados y, en su vista, una sociedad de personas competentes, representantes de las cuatro provincias hermanas, formaría luego el diccionario general de nuestro antiguo reino (Valladares 1884: VI). 
Esta misma idea la subscribe J. Cuveiro en la introducción a su Diccionario:

\begin{abstract}
Algunos amantes de nuestra literatura patria han manifestado en varias ocasiones la conveniencia de reunirse en un centro dado cierto número de personas de cada una de las cuatro provincias y aun de los partidos judiciales, para que, provistos de datos, pudiesen arreglar un verdadero diccionario; pero es preciso confesar que para esto se requiere, además de una iniciativa eficaz, un patriotismo, constancia y decisión a toda prueba, y que solo podría llevarse a cabo si de las Diputaciones provinciales partiese el empeño de conseguirlo (1876: [s. pag.]).
\end{abstract}

De aquí a reivindicar la institucionalización de una "Academia" que liderase y legitimase un proyecto semejante, en la línea de la RAE, no había más que un paso. Por eso comienzan a detectarse sugerencias en este sentido a partir de 1875. Uno de los primeros en formularla abiertamente es el poeta y publicista Valentín Lamas Carvajal, quien en la novena de las Dez cartas escritas pr'os gallegos, publicadas este mismo año, anima a hablar gallego "pois non é mancilla", y añade:

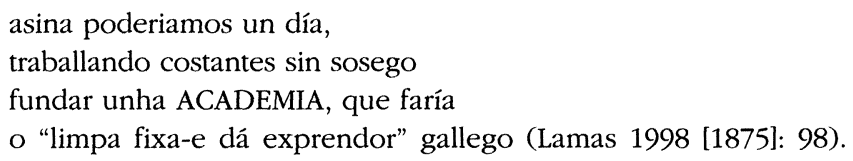

Mucho más explícito es A. Elías Martínez, quien, haciéndose eco de la anarquía que en su opinión caracterizaba la "literatura regional", por la ausencia de un "diccionario completo" y de obras literarias que pudiesen servir de modelo (un argumento previamente utilizado por Saco y Arce), defendería en un artículo seriado en $\mathrm{El} \mathrm{Heraldo} \mathrm{Gallego,} \mathrm{a} \mathrm{finales} \mathrm{de} \mathrm{los} \mathrm{setenta,} \mathrm{la} \mathrm{crea-}$ ción de una Academia gallega, a la que le asignaba las siguientes funciones:

\footnotetext{
Los trabajos que emprendería la Academia gallega serían de incalculable trascendencia para nuestra literatura regional. La confección de un Diccionario completo: publicación de una Revista, escrita en gallego [...] propaganda activa y constante de los refranes y cantares populares [...] publicación de un compéndio de la Gramática gallega [...] y por último, coleccionar en un tomo las poesías gallegas de los escritores conocidos, que por su mérito especial, pudieran servir como de base para el cultivo y perfeccionamiento de nuestra lengua (27 [5.6.1879] y en Hermida 1992b: 198).
}

La misma Pardo Bazán aprovecharía una reseña sobre un poemario de V. Lamas Carvajal, Saudades Gallegas (1880), para proponer también ella en su Revista de Galicia la idea de una "Academia de la lengua gallega [...] que no escasean elementos para fundarla, ni á mí me faltará nunca constancia para seguir rogando á los que son capaces de constituirla, que se unan y limpien, 
fijen y dén esplendor á esta habla" (11 [10.6.1880]). En las páginas del diario Gaceta de Galicia se informa de que en 1885 se constituiría una Academia gallega, dividida en varias secciones: Historia, Bellas Artes, Ciencias y una dedicada a la Lengua y a la Literatura; esta última tendría unos objetivos muy parecidos a los sugeridos por Elías Martínez: "fundir en uno solo los subdialectos provinciales, escribir la gramática y el diccionario; publicar las obras clásicas de nuestra literatura; dirigir los certámenes populares; llevar al teatro nuestras producciones y enseñar á nuestros hijos las leyendas, tradiciones y costumbres de un pueblo cuyo origen es tan glorioso" (1682 [22.11.1884]). Este proyecto no llegaría a materializarse. Tres años más tarde en Galicia, Revista Regional, Aureliano Pereira, un distinguido federalista, alentaba la creación de una Academia gallega como la institución más apropiada para la elaboración de un diccionario y una gramática como instrumentos de autoridad referencial: "Se necesita un buen 'Diccionario', y una buena 'Gramática'; obra que no creemos sea bastante á realizar con el grado de perfección que se necesita, una sola persona, por grande que sea su voluntad. Para tal trabajo se necesita la asociación que lo hará mucho más llevadero y completo" (2 [febrero, 1887] y en Hermida 1992b: 277).

La reivindicación de una Academia como solución a los problemas de normalización lingüística del gallego llegó a hacerse tan presente entre las élites culturales que la imagen de la autoridad académica es utilizada incluso para ironizar (y defenderse) frente a las críticas ajenas, como ejemplifica la respuesta en la revista $A$ Monteira de Amador Montenegro a Amor Meilán, quien lo había acusado por el uso de castellanismos: "¿E qué pensa que tales palabras non son gallegas? ¿Quén lle deu autoridá pra decraralo así, doumáticamente? Porqu'o Sr. Meilán en tal caso xa non autua de maestro, sinon d'Academia, si señor, d'Academia en pleno, qu'é canto acurrírselle pode a un Meilán" (58 [8.11.1890]).

O Galiciano pontevedrés, una de las publicaciones más plenamente identificadas con el regionalismo cultural gallego de finales del XIX, no podía faltar a esta cita. En la primavera de 1889 apuesta también por la "Creación d'unha Academia d'a fala gallega", señalando los "valiosos elementos" que justificaban tal empresa y que podían servir como punto de partida para su institucionalización:

A istes fís fecundos se encamiña o pensamento comprendido n-estas líneas: pra levalo a término contamos hoxe en día cal nunca, con valiosos elementos; antre moitos que se poden citar, a gramática gallega de Saco y Arce, [...] o apreciable e utilísimo diucionario d'o Licenciado Valladares, Gaita Gallega de Xan Manoel Pintos, a coleución de poesías de doña Rosalía Castro, de Añon, de Posada [Benito Losada?], de Ferreiro etc., etc. e os diferentes pródicos publicados en tod'o territorio gallego. A Academia de que se trata comporase de persoas ilustradas e competentes, 
que deberán ocuparse en confeucionar un diucionario gallego-castellano e-o correspondente castellano-gallego (218 [14.4.1889] y en Hermida 1992b: 376).

Como Saco y Arce en el prólogo a su Gramática, los editores de $O$ Galiciano consideraban fundamental la confección de un diccionario gallego/ castellano y castellano/gallego. Un tercer paso, el de un diccionario gallego/ gallego, era una reivindicación casi inimaginable en la época y tendría que aguardar casi un siglo para su entrada en el "paisaje lexicográfico" gallego ${ }^{12}$. $\mathrm{Ni}$ la creación de una Academia ni la elaboración de un "Diccionario" institucional, objetivos tan insistentemente reclamados en la segunda mitad del XIX, serían realidad hasta principios del siglo siguiente. M. Murguía, que había sido uno de los pioneros, como en tantos otros aspectos del "Rexurdimento" cultural gallego, en lamentarse de la falta de un diccionario gallego, publicaría en setiembre de 1904, en La Temporada en Mondariz, un trabajo con el significativo título de: "Diccionario de la lengua gallega. Necesidad de su formación y publicación"13, que tendría un protagonismo decisivo en la creación de la Academia gallega (establecida dos años más tarde, en septiembre de 1905). En un tono más proyectivo-reivindicativo que analítico o filológico, el que luego sería su primer presidente da vida en este artículo a una serie de aspectos que la intelectualidad galleguista había heredado de las reivindicaciones sociolingüísticas y culturales decimonónicas. Murguía considera insuficiente la publicación de libros en gallego:

para que todo esto contribuya á su afianzamiento y cultura, se necesita más. Hace tiempo que está pidiendo el país que las personas habilitadas para ello, se arriesguen á la publicación de obra en que brille el más exacto conocimiento de nuestra lengua, pero sobre todo que tomen sobre sí el penoso y arriesgado empeño de dar á luz un Diccionario, en que se compendie toda la riqueza y hermosura del idioma propio (Murguía 1905:1).

Con una propuesta semejante, Murguía estaba obligado a hacer un rápido escrutinio de los diccionarios y vocabularios ya existentes. Alude al pro-

${ }_{12}$ Cuando entre 1907 y 1908, en el seno de la recientemente instituida Academia Gallega (1905), se establecen los principios operativos para llevar adelante el proyecto lexicográfico del primer diccionario académico, una de las cuestiones que se va a debatir es si este debería ser sólo gallego-gallego o gallego-castellano, como en los repertorios lexicográficos precedentes. La resolución de la comisión encargada de estudiar este aspecto es reveladora de la pervivencia del bilingüísmo subalterno: ya que el diccionario no iba a ser para uso exclusivo de los gallegoparlantes, argumentan los académicos, se apuesta por el modelo gallego-castellano. Este dato habla de la lenta o casi nula evolución experimentada por los presupuestos con los que venía operando desde mediados del siglo xIX el discurso lexicográfico gallego.

${ }^{13} \mathrm{El}$ artículo sería reproducido en abril del año siguiente en la revista cubana Galicia (14 [2.4.1905]) de la que se toman las citas. 
yecto de J. Sobreira en el siglo XVIII, pero sobre todo al "fecundo finado siglo decimonono", en el que destaca las figuras de Saco y Arce y J. M. Pintos, porque abrigaron la idea de recopilar el corpus lexemático gallego, y $\mathrm{F}$. J. Rodríguez, J. Cuveiro y M. Valladares, de los que hace la siguiente valoración: "del bibliotecario Rodríguez logróse impreso el breve trabajo que dejó a su muerte y que en realidad apenas si importa como subsidio. El de Cuveiro es más extenso, pero deja bastante que desear, y fue sustituído con fortuna por el más copioso e importante de Valladares". Ninguno de los tres respondía a las exigencias lexicográficas de principios del siglo xx, y distaban de la concepción del diccionario que Murguía con toda probabilidad vislumbraba como modelo para el proyecto lexicográfico de la futura Academia gallega:

Ninguno de ellos [...] llena el vacío que se siente de un Diccionario hecho conforme á los adelantos actuales y [en] el cual, no sólo se hallen las voces corrientes, sino que se señalen las arcaicas, valiéndose para ello del gran caudal que atesoran nuestros documentos medioevales, señalando al paso las infinitas semejanzas que existan entre las palabras gallegas y francesas, por importantes y numerosas (Murguía 1905:1).

Este sería, en líneas generales, el punto de partida para la elaboración del primer diccionario de la Academia gallega, que habría de quedar inconcluso. Este repertorio lexicográfico no pasaría del lexema "cativo", después de incontables dificultades institucionales y económicas ${ }^{14}$.

\section{LAS PUBLICACIONES PERIÓDICAS}

El creciente interés por los estudios gramaticales y por los compendios lexicográficos tenía su razón de ser en los argumentos y contra-argumentos centrados en la cuestión del grado de estandarización del gallego, su condición de "idioma" o "dialecto", el nivel de canonicidad literaria logrado por sus autores más representativos, su transformación de vehículo de expresión oral en instrumento autosuficiente de una cultura impresa y la conversión de una cultura rural y privada (invisible) en una cultura urbana y pública; de ahí la constante reivindicación de publicaciones periódicas monolingües o, por lo menos, con un alto nivel de contenidos en gallego. No debe extrañar que sea El Heraldo Gallego (1874-1880), la publicación periódica dirigida por el polifacético escritor y publicista Lamas Carvajal, un espacio cultural privilegiado para detectar las principales corrientes de preocupación compartidas por muchos de los regionalistas de la época. Es sintomática, tanto de las necesidades que se sentían, como de los nuevos objetivos que se empeza-

${ }^{14}$ Para una excelente visión de conjunto sobre las condiciones de elaboración del primer diccionario de la RAG ver Seoane Sánchez (1999). 
ban a plantear en este incipiente espacio público, la siguiente nota extraída de esta revista: "Como carecemos de poetas clásicos, como aun no hemos llegado á fijar nuestra literatura regional, como no tenemos un diccionario perfecto donde poder consultar las dudas que se nos ocurran acerca de la pureza del lenguaje; de ahí esa anarquía que reina entre todos los escritores gallegos" (31 [10.6.1878]). Unos años más tarde, la función legitimadora y normativa de los diccionarios parece haber logrado una incuestionable vigencia, como se detecta en las siguientes líneas tomadas de la primera publicación periódica en gallego O Tío Marcos de la Portela (1876-1880, 1883-1889), dirigida también por Lamas Carvajal: "Nos dous diccionarios que temos pode atopala [la palabra 'pobo'] sin moito traballo" (22 [13.4.1884]); un claro ejemplo de cómo los diccionarios en la década de los ochenta comenzaban a funcionar como legítimos instrumentos de referencialidad para los comportamientos lingüisticos. Este creciente clima de (jjustificado?) optimismo es recogido a finales de esta misma década en otra publicación periódica, Galicia. Revista Regional: "Poseemos en el día gramáticas, diccionarios y poesías de primer orden, y lo hablan millones de habitantes" (1 [enero,1888]). Lo que silencia esta nota es que esos "millones" de hablantes, en su mayoría de procedencia rural, carecen del necesario capital político, económico y social para hacerse oír en la España de la Restauración.

En una amigable polémica con otros periódicos gallegos sobre la necesidad de lanzar una campaña de propaganda para el uso del gallego escrito, liderada por El Heraldo, consistente en la recomendación de que semanalmente cada publicación periódica destinase una sección a composiciones en prosa y verso escritas en gallego, así como a la reproducción de refranes y cantares populares, salen a la luz algunos de los instrumentos que legitimaban la entidad sociocultural del gallego. A El Diario de Lugo, por ejemplo, le informa El Heraldo de que Galicia. Revista Universal de este Reino (18601865) había publicado en 1863 "un diccionario gallego castellano, recopilado por el difunto Pbro. D. Francisco Javier Rodríguez, que no por ser excesivamente incompleto, deja de tener utilidad extrema. Por último, el Sr. Cubeiro Piñol acaba de publicar un diccionario gallego, que por hoy no conocemos"15. Unos días más tarde publica otra nota de contenido semejante, esta vez dirigida a El Diario de Ferrol, en la que se afirma que ni F. Rodríguez ni Cuveiro, autores de los dos diccionarios "con que hoy contamos, han hecho las preguntas que nuestro colega hace, ignoramos con que objeto, y se limitarían únicamente a recoger las palabras gallegas, pero sin pararse a examinar escrupulosamente las distintas fases que haya sufrido la frase ó vocablo"

15 Este último había sido publicado en Barcelona en 1876, y el artículo saldría a principios del año siguiente (10.2.1877). 
(20.2.1877); esta observación venía motivada por el argumento, formulado unas líneas antes, en el que se defendía el uso del gallego "que se conoce actualmente, si bien con algunas imperfecciones, efecto del abandono en que ha vivido y del limitado número de escritores que lo han cultivado", frente a las disquisiciones pseudohistoricistas formuladas por el diario ferrolano, que no eran sino un pobre argumento para devaluar la propuesta de revitalización sociolingüística sugerida por El Heraldo. Se observa en estos intercambios una preocupación por dirigir los proyectos lexicográficos a la fijación de un corpus lingüístico funcional. La elaboración de un diccionario histórico era, por múltiples razones, un objetivo lexicográfico secundario en la Galicia de finales del siglo XIX.

La visible atención que se le concede a la esporádica publicación de los diccionarios en la Galicia de la Restauración, sobre todo en los medios de comunicación identificados con la causa regionalista, se hace una vez más patente en El Heraldo Gallego, con un artículo seriado (entre octubre y diciembre de 1877), firmado por J. Soto Campos, y titulado precisamente "Diccionario gallego", en el que se analiza en detalle el trabajo lexicográfico (1876) de J. Cuveiro. En primer lugar, subraya el autor una característica negativa compartida por todos los proyectos lexicográficos de la época: la perpetuación del bilingüismo subalterno ("las palabras gallegas que trata de definir no las define en gallego, sino en castellano"), por eso le niega la condición de "diccionario gallego": "Creemos, pues, que para que la obra del Sr. Cuveiro pudiese llevar con propiedad el nombre de Diccionario gallego debería estar escrita en lengua gallega, pues en otro caso no pasa de ser un diccionario gallego-castellano" (18 [10.10.1877]). La conclusión, aplicable por igual a muchos otros proyectos lexicográficos gallegos, es la lógica: "Esta obra parece estar escrita especialmente para las personas poco versadas en la lengua gallega, pues de otra manera no se comprende, muy bien que digamos, la necesidad que tuvo su autor para escribirla en castellano" (Ibid.). Las objeciones subsiguientes son más específicas: la ausencia de notas biográficas sobre autores gallegos, una práctica común en los diccionarios generales de la época; y lo excesivo del precio ("se vende el ejemplar á 20rs") para el número de entradas que ofrecía el diccionario. Finalmente, y en relación con este mismo tema, se hace alusión, en un tono ciertamente irónico, a las tan debatidas ayudas públicas por parte de las Diputaciones: "Se nos dirá que para contener tantas voces un diccionario, se hace mas costosa la obra de que se trata; es verdad, pero ¿y là ayuda de las Diputaciones gallegas? ¡Vamos que con unas Diputaciones tan buenas como tuvo el Sr. Cuveiro ... ya se puede hacer un sacrificio" $(28[5.12 .1877])^{16}$. En este sentido hay que añadir que la

${ }^{16}$ Subrayado en el original. 
Diputación de A Coruña se negó a comprar ejemplares del diccionario de $\mathrm{J}$. Cuveiro para no verse así afectada por el desprestigio sociocultural asociado al cultivo (y defensa) de la lengua gallega, pero sobre todo para silenciar cualquier intento de reivindicación galleguista, que las instituciones oficiales consideraban como un atentado contra la unidad del Estado ${ }^{17}$.

El mismo Soto Campos se encargaría, unos años más tarde, de evaluar la aportación del diccionario de M. Valladares en una breve reseña publicada en Los Sábados de El Anunciador de Pontevedra ${ }^{18}$. La recepción de este diccionario en los años inmediatos a su aparición se centró en dos aspectos: por una parte, la contribución específica de M. Valladares al incipiente corpus lexicográfico de la época; y por otra, el estudio de este diccionario para subrayar aspectos específicos de la dinámica sociolingüística gallega en un momento en el que la producción editorial de esta lengua iniciaba un apreciable despegue, sobre todo a partir de 1880. Las evaluaciones fueron en general positivas, incluso por parte de los que cuestionaron la propuesta ortográfica de M. Valladares. La de Soto Campos, titulada "Dos palabras sobre un nuevo libro", saluda la publicación del diccionario, no sin antes precisar que le parecía "muy incompleto y bastante salpicado de herejías" el de J. Cuveiro. Sin considerarlo "un diccionario que llene por completo las necesidades de los que se dedican á escribir en la lengua de Macías", justifica las deficiencias del de $\mathrm{M}$. Valladares con un argumento muy frecuentado en la época: "que el libro del Sr. Valladares no satisfaga por completo á nadie deberá extrañar porque al fin y al cabo es producto solo de su trabajo, de su inteligencia, sino estamos mal enterados". Para Soto Campos, como para tantos otros regionalistas de la época, la superación de esta deficiencia estaría en la constitución de una "Academia compuesta de las personas más instruídas en la materia y más entusiastas al mismo tiempo por el perfeccionamiento del gallego" (en Hermida 1992b: 251-52).

En su incansable lucha en defensa y reivindicación del gallego las páginas de El Heraldo Gallego acogerán artículos-manifiestos, como el de Laureano Rodríguez, que terminaba con la siguiente invitación: "Aprendamos el gallego, hablémoslo; pues tenemos para llegar al logro de ese importante objeto dos poderosos auxiliares en la filosófica Gramática del Sr. Saco y Arce, y en el compendiado Diccionario de D. Francisco Javier Rodríguez" (51 [20.11.1878]).

${ }^{17}$ Se sabe que la Diputación de Ourense, por el contrario, y según se recoge en el Heraldo (13 [15.3.1877]), compró un número de ejemplares del diccionario de Cuveiro.

${ }^{18} \mathrm{El}$ texto nos llegó sin referencia de fecha. Casi con toda seguridad fue publicada en 1884, año en que sale de la Tipografía del Seminario Conciliar de Santiago el Diccionario de M. Valladares. La cita está tomada de la muy útil antología $A$ reivindicación da lingua galega no rexurdimento (1840-1891). Escolma de textos, preparada por Carme Hermida (1992b). 
La Ilustración Gallega y Asturiana (1879-1881), otra de las publicaciones emblemáticas de la época, y dirigida por M. Murguía, no podía mantenerse ajena a la preocupación por la lexicografía gallega, y más concretamente por la elaboración del "diccionario", entendido éste como la recopilación del fondo lexemático de una determinada lengua, estuviese ésta caracterizada en términos de "idioma" o de "dialecto". El estudioso asturiano A. Balbín de Unquera, por ejemplo, se hace eco del enorme interés que en toda Europa despierta el estudio de los dialectos en un artículo titulado "Cómo deben cultivarse los dialectos?"19 y analiza su viabilidad, que considera directamente relacionada con el apoyo legitimador que le concede la existencia de una gramática y de un diccionario: "Si se cuenta con gramáticas y vocabularios [...] los dialectos vivirán indefinidamente", afirma categóricamente. Antes ya había apuntado esta misma idea al indicar que "los euskaros como los catalanes han podido y todavía pueden ofrecer diccionarios y gramáticas dignos del mayor aprecio para los españoles, y bastante completos para dar a conocer la lengua y la literatura á los extranjeros" (28 [8.10.1880] en Hermida 1992b: 213-218).

Añade Balbín un par de observaciones que muestran la modernidad de algunas de sus propuestas, como por ejemplo, las deficiencias de un "diccionario" basado exclusivamente en la producción poética (=literaria) de un idioma, es decir, en un corpus lexicográfico extraído de la literatura "culta"; también señala la potencial aportación del portugués al corpus lexemático del gallego; según el autor del artículo "este elemento haría, no sólo más rico su Diccionario, sino también más enérgica su frase” (Ibid.).

$\mathrm{Al}$ año siguiente, y también en La Ilustración Gallega y Asturiana, el mismo autor publicaría otro artículo con el título de "Estudios lingüísticos. El portugués y el gallego", en el que señala las ventajas del primero sobre el segundo, cifradas fundamentalmente en la legitimación del portugués como "idioma oficial á un Estado independiente", una condición que redundaría necesariamente en la producción de diccionarios y obras etimológicas, de las que carecía el gallego, lógicamente, porque "no se hacen trabajos tan difíciles sin una protección especial muy de veras concedida al que los emprende" (27 [28.9.1881]); de ahí el deficiente estado en el que se encontraba, según Balbín, la recopilación lexemática gallega a principios de los ochenta. Y añade una observación final sobre las inevitables correlaciones entre la dimensión escrita de una lengua, su grado de legitimación social y su transcripción en un corpus lexicográfico:

La mayor parte de los dialectos se hablan más o menos por diferentes clases de la sociedad, pero apénas se escriben, y la escritura es la que fija las lenguas, es la

19 Ver M. Mourelle-Lema (1968) para más información sobre el interés de los lingüistas decimonónicos por los dialectos. 
encargada de elegir entre los varios elementos locales los más adecuados para formar parte del Diccionario [...] He aquí otros tantos medios de progreso para el portugués, que absolutamente han faltado al dialecto gallego (Ibid.).

Esta misma idea, explícita o implícitamente formulada, está en el origen de la mayoría de los estudios-manifiestos filológicos gallegos a finales del siglo XIX, en los que se detecta, cada vez con mayor intensidad, la tensión entre el gallego escrito y el oral como ámbitos de legitimación cultural.

\section{HACIA UN DICCIONARIO NORMATIVO}

Pero a la altura de la década de 1880 sigue echándose de menos un diccionario como instrumento de referencia, consulta y guía. En su estudio sobre el poemario de Curros, titulado Juicio crítico a "Aires da miña terra" de M. Curros Enríquez (1883), W. Álvarez Insua se lamentaba de la inexistencia de gramáticas, aunque reconocía el trabajo "bastante aceptable" de Saco y Arce, pero echaba sobre todo de menos un diccionario donde los escritores pudiesen encontrar "una verdadera fuente del gallego puro y sin mezclas lugareñas", lo que le lleva a considerarlo como un "dialecto". Aprovecha para animar a Marcial Valladares a terminar su proyecto lexicográfico, que sería publicado al año siguiente (Álvarez Insua 1883: 26 y en Hermida 1992b: 234).

El problema no se limitaba a la carencia de obras lexicográficas o gramaticales, porque las pocas que se iban publicando no lograban ni la legitimación ni el respaldo necesarios para asegurar su funcionamiento como "autoridades". Los comentarios formulados por "A. Marsal" a finales de los ochenta en Galicia. Revista Regional dan una idea de la problemática aceptación de dos de los diccionarios existentes, el de Cuveiro y el de Valladares, en su dimensión ortográfica; señala el articulista que "la ortografía empleada por ambos publicistas en sus respectivos 'Diccionarios' [...] no [la] adoptó la gran mayoría de los escritores gallegos, circunstancia que en otro país haría dudar de su fundamento" (4 [abril, 1888] y en Hermida 1992b: 301) ${ }^{20}$. El articulista señala aquí uno de los rasgos fundamentales del discurso lexicográfico, emblematizado en el objeto "diccionario": su función hegemónica como transmisor de una ideología, generalmente identificada con las clases dominantes. La deficiencia de los diccionarios gallegos en este sentido habla claramente de una compleja situación sociolingüística en la que los mecanismos de producción y reproducción cultural identificados con la promoción de una identidad colectiva, entendida en términos regionalistas, carecían de los medios

20 "A. Marsal" era el seudónimo de A. Martínez Salazar, destacado publicista y animador cultural en la Galicia de finales del XIX. 
necesarios para asegurar su institucionalización. Podría decirse incluso que todo el "Rexurdimento" gallego, como un proyecto de reivindicación, se quedó a medio camino entre la fase inicial constitutiva, fundamentalmente programática, y su concreción institucional. Las citas recogidas en la sección de este trabajo dedicada a los múltiples y frustrados llamamientos para la creación de una Academia ofrecen un claro testimonio de este fenómeno.

En un artículo publicado unos meses más tarde en la misma revista, "A. Marsal" se muestra más generoso con las obras lexicográficas gallegas. Esta vez, la aludida carencia de autoridad de los autores de gramáticas y diccionarios gallegos tiene su origen no en una cuestionable ortografía, sino en un hipotético "individualismo suevo digno de mejor causa" que detecta en muchos escritores gallegos; y se pregunta inmediatamente si no habrá algo de valor en los trabajos de Saco y Arce, J. Cuveiro, M. Valladares y A. de la Iglesia (en su condición de responsable editorial del diccionario de $\mathrm{F}$. Rodríguez); la respuesta es generosamente afirmativa, sobre todo cuando, como él señala, se tienen en cuenta las circunstancias en las que fueron elaborados:

Valen, en mi concepto, tanto más cuanto que se han realizado en un espacio de tiempo relativamente corto y en un país que ha tenido en el más completo abandono, durante siglos, su idioma, y donde, en la actualidad, son muy pocas las personas que saben leerlo y escribirlo. No dudo de que se hayan equivocado alguna vez aquellos apreciables autores [...] ¡Quién nos diera, amigo mío, un diccionario gallego á la altura del castellano con sus defectos y todo! (6 [junio, 1888] y en Hermida 1992b: 334-335).

La relevancia que le asignan los regionalistas gallegos al "Diccionario" era la consecuencia lógica de una creciente y apremiante preocupación por normativizar el gallego en todos los ámbitos socioculturales, una conquista fundamental para legitimar los idearios galleguistas en aquellos años. Esta nueva dimensión de los estudios lexicográficos explica que las declaraciones sobre la urgente incorporación de proyectos lexicográficos a la dinámica sociocultural gallega del momento distasen de la intencionalidad anticuarista de las décadas anteriores ${ }^{21}$.

Los distintos sectores galleguistas demandaban una articulación que permitiese fijar los usos de la lengua en todas sus dimensiones, sobre todo en

${ }^{21}$ La legitimación sociolingüística derivada de los estudios gramaticales y de las compilaciones lexicográficas es una constante a lo largo de estos años. Así, se puede leer en $O$ Galiciano: "Contamos tamén hoxe c'unha gramática e dous diucionarios gallegos que, si bên non satisfán por compreto as necesidás cubizadas, non podemos tampouco negarlle os grandes beneficios que nos veñen prestando, s'atendemos às pequenas diferenzas que d'unha á outra provincia, y-hastra d'un á outro pobo, se reconocen n-a môr parte d'as palabras de que se compòn á nosa dòce fala" (39 [23.5.1885]). 
la ortográfica; en parte, porque muchos de los argumentos esgrimidos por los que favorecían la extinción del gallego utilizaban como prueba las aparentes disparidades e incoherencias de los textos escritos por los que defendían y pretendían legitimar su supervivencia, pero sobre todo su consolidación como un legítimo instrumento de comunicación social y expresión cultural. En esta crítica eran incluidos también los diccionarios y vocabularios que no podían sino reflejar los mismos problemas de desarticulación lingüística (y cultural) exhibidos por las otras modalidades de la letra impresa en gallego. "If 'the dictionary' may be considered a monument in the architecture of cultural dominance", como sugiere R. DeMaria Jr. en su análisis del Dictionary de Samuel Johnson (1989: 71), la experiencia lexicográfica gallega del siglo XIX demuestra que la efectiva instrumentación del diccionario requiere un marco institucional en el que la imagen social de la lengua correspondiente esté plenamente identificada con su condición de "idioma nacional". Es importante no olvidar, como recordaba Balbín de Unquera en las páginas de la La Ilustración Gallega y Asturiana, que no todos los diccionarios están dotados de (o respaldados por) una autoridad institucionalizada, sea esta pública o privada.

Por eso, el discurso lexicográfico gallego del siglo XIx tenía como objetivo fundamental la elaboración de un diccionario muy específico, que se corresponde con el tipo que L. Zgusta (1989: 70) designa como "standardcreating dictionary", y cuyo fin era articular y legitimar una normativa (léxica pero también ortográfica) para la lengua impresa, porque el éxito de la propuesta de un gallego estandarizado, que estaba en la mente de los provincialistas y regionalistas, dependía de su capacidad para legitimar una rica variedad de registros con la que el escritor gallego pudiese hacer frente a los múltiples desafíos representados por la articulación cada vez más autónoma de los discursos sociales (el literario, pero también el historiográfico, el económico, el ideológico, el político...) que constituían el armazón del letrado y del ideólogo de la segunda mitad del siglo XIx. De ahí la relevancia del discurso lexicográfico en el marco contextual del "Rexurdimento".

Es famoso el poema de A. de la Iglesia, "Ortografía gallega", publicado en Galicia Humorística en un año especialmente fértil en polémicas ortográficas $^{22}$. En esta composición se intenta justificar y legitimar una propuesta ortográfica, como indica el mismo título de la composición, invocando algunas de las "autoridades" lexicográficas de la época:

\section{Rodriguez, bibliotecario}

D'a Universidad' ilustre

\footnotetext{
${ }^{22}$ Puede consultarse con provecho Carme Hermida (1987), para un detallado análisis de las diferentes posiciones que se dan cita en este encendido debate.
} 


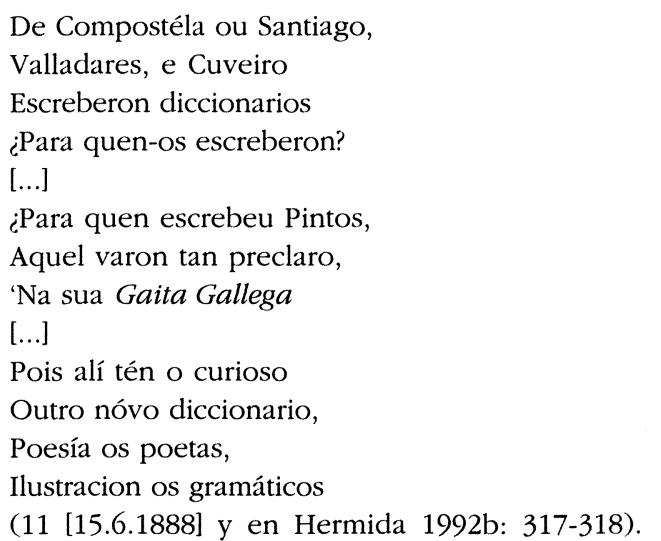

La propuesta de la Iglesia fue objeto de críticas, algunas ad hominem; por ejemplo, en la revista $O$ Tío Marcos da Portela aparece en los meses de julio, agosto y setiembre de 1888 un artículo seriado, bajo el título genérico de "A cuestión da X", firmado por Alberte Vidueiros (en Hermida 1992b: 353-362); el autor aprovecha algunas notas de su trabajo para descalificar el sistema ortográfico del autor de El idioma gallego, metiendo en el mismo saco a M. Valladares: "Si el señor d'a Igresia se houbese tomado a molestia de buscar n-o Diccionario de Cuveiro esa palabra [hoxe], houbéraa atopado escrita con 'equis' como debe estar, y non daría esa primeira zoupada etimolóxica. É verdá que n-o Diccionario de Valladares aparece con 'jota', pro o que lle digo á un dígollo a outro, e que me perdoen os dous". Después de señalar la efectiva intervención de las "sábias corporaciós" en España y en Francia en la dotación de "bós Diccionarios" para el castellano y el francés, se pregunta el articulista si se deben consultar los diccionarios gallegos; la respuesta es afirmativa, pero no sin ciertas reservas, sobre todo en lo tocante a la ortografía:

¿Consultarémos os Diccionarios gallegos? Tres temos [los de Rodríguez, Cuveiro y Valladares] pol-o d'agora e nunca pagará Galicia ôs seus autores o ben que co-a sua pubricacion lles fixeron. Pro non por eso habemos de consideralos perfeutos, nin podian selo, posto que foron nados por obra úneca d'o esforzo individual. E no tocantes â ortografía non poden servirnos de regra, pois non solo difiren esencialmente os ús d'os outros, sinon qu'en todos eles a ortografía etimolóxica anda mui descuidada como non podía ser menos. Así é que si me vexo obrigado á porlles defeutos, non deixo de recoñecer por eso que foron precisos moito traballo e moita intelixencia pr'a sua formación, que son de utilidade innegabre pro país e seus escritores, e unha sólida base sobr'a que, andando os tempos e con sucesivas melloras ha d'asentarse o nobre edificio d'a lengua gallega (Ibid.).

E insistiendo una vez más en la cuestión ortográfica, compara la representación gráfica de varias palabras en los tres diccionarios para "que se vexa 
non solo as faltas que n-os nosos Diccionarios se cometen contra a escritura etimolóxica, sinon a pouca conformidá que hay entre todos eles"; y concluye: "non podemos guiarnos pol-os Diccionarios que temos, porque non hai entre eles ainda o acordo que se precisa nin bastante esautitude n-os seus datos" (Ibid.). Estas declaraciones muestran claramente que la producción lexicográfica gallega, así como las interpretaciones que de ella se estaban realizando, entraban en una fase de inestabilidad crítica a finales de siglo. Si, por una parte, se reconocía el enorme esfuerzo de recopilación lexemática, siempre individualizado y con unos medios (y preparación) mínimos, por otra, el resultado de los diccionarios que se iban publicando era considerado muy deficiente, e incluso contraproducente, porque parecía abundar en los argumentos antigalleguistas del momento.

Pero si las propuestas de A. de la Iglesia (y M. Valladares) tenían sus detractores, contaban también con ilustres defensores, entre ellos el destacado estudioso de la literatura popular gallega J. Pérez Ballesteros, quien reconocía en las páginas de Galicia. Revista Regional "estar conforme con algunas apreciaciones del ilustre escritor señor Valladares, autor del último Diccionario gallego" (9 [agosto, 1888] y en Hermida 1992b: 366) ${ }^{23}$. R. Pesqueira Crespo, otro colaborador de O Tío Marcos da Portela, respondía también a las preocupaciones del momento con un artículo en esta revista, titulado "Cuestiones de actualidad", en el que entre otras cosas decía:

Si hoy en nuestro dialecto, gracias a los esfuerzos de la Iglesia, Valladares, Barreiro Meiro y algún otro, se descubren heridas procedentes del abandono en que vivió por tantos años, lo que ha de procurarse es administrarle el bálsamo cicatrizante de la etimología ó del fonetismo ... Purgar el idioma de los errores que pudo haber admitido en el discurso de los tiempos, reglamentarle con Gramáticas y Diccionarios. (8 [agosto, 1888] y en Hermida 1992b: 373).

Al diccionario y a la gramática se le asigna ahora una función claramente normativa y de "purga", como instrumentos dirigidos a eliminar, mediante el criterio etimológico y el fonético, los elementos espurios que se habían ido imponiendo como resultado del "abandono" multisecular en que había vivido el gallego. La metaforización médica empleada por el articulista es altamente significativa de la lectura que en aquellas décadas se hacía del fenómeno sociolingüístico gallego.

${ }^{23} \mathrm{El}$ apoyo de J. Pérez Ballesteros es especialmente significativo porque este autor contaba en 1888 con dos poemarios publicados, un dato altamente significativo en el panorama literario gallego de la época, pero sobre todo con una obra de erudición, el Cancionero popular gallego y en particular de la provincia de La Coruña (1885-1886) en tres tomos, que le valió varios premios internacionales y le aseguró fama internacional como folclorista. 
$\mathrm{Al}$ año siguiente en el Álbum literario de Ourense el mismo autor, en una breve nota sobre la creación de una Academia como solución a algunos de los problemas con los que se encontraba el gallego en su imperiosa y urgente necesidad de apropiarse de un mínimo de legitimidad para funcionar con efectividad, se lamentaba de la desmembración del idioma y de la falta de cooperación y coordinación en los filólogos y escritores: "En Galicia, triste es confesarlo, cuanto no sea miserable lucha de partidos, cuanto no entrañe interés político, merece el desprecio; solo así podríamos explicarnos el abandono en que yace nuestro idioma dividido en tantos diccionarios y gramáticas como son las personas que se dedican á su cultivo" (70 [2.6.1889] y en Hermida 1992b: 382).

La preocupación lexicográfica experimentada en esta década, y refrendada por algunas de las propuestas ya citadas sobre la necesidad de una Academia que articulase proyectos de recopilación lexemática, sería apoyada por otras sugerencias, como la que M. Pardo Becerra había formulado en la revista $A$ Monteira en 1889 , y que tenía como objetivo la plena difusión del idioma a través de la prensa y la consagración de los estudios lexicográficos en los certámenes culturales:

Se fai necesario un médeo pra que sexa de todos ou d'a maor parte conocidal-as moitas y moi sinificativas palabras que n-él s'atopan, pr'o ningunha cousa me parez mais d'o caso qu'o qu'aparezan n-as colunas de todol-os peródicos con mais frecuencea, esquirtos n-o noso idioma [...] o mellor seria que n-os certames que tan a miudo se celebran, se puxesen temas filolóxicos, ou lexicográficos (10 [7.12.1889] y en Hermida 1992b: 392-393).

Sin embargo, como demostración de la relevancia asignada al diccionario y a la gramática como instrumentos fundacionales y legitimadores de un idioma a finales de siglo, pocos textos son tan reveladores como el prólogo que $\mathrm{J}$. Barcia Caballero escribió para sus Rimas (1891), en el que se enfrenta a quienes consideraban que "esto de la literatura gallega no es más que fantasía, puesto que el gallego apenas existe como idioma literario". Su defensa se apoya en "la historia y los hechos, con su autoridad la una y su contundente persuasiva los otros"; pero por si esto no fuese suficiente, añade Barcia Caballero, "bastaría a darle carta de naturaleza el poseer los 'dos documentos' que acreditan de tal á un idioma cualquiera: una gramática y un diccionario, excelentes ambos por cierto y que honran á sus autores y al idioma que los posee" (Barcia 1891: XXXIII-XXXIV y en Hermida 1992b: 401).

\section{NOTA FINAL}

Que los intelectuales galleguistas de la segunda mitad del siglo XIX aboguen insistentemente por la elaboración (y publicación) de un diccionario de 
la lengua gallega es una reivindicación en la que se dan cita, por los múltiples intereses y presupuestos que en ella coinciden, los diferentes elementos que constituyen el horizonte ideológico del movimiento "rexurdimentista" iniciado en la década de los cincuenta. Por eso, para entender las constantes demandas lexicográficas de la época, representadas emblemáticamente en la reivindicación de un "Diccionario gallego", hay que relacionarlas con el clima sociocultural "provincialista" y "regionalista" que experimenta la Galicia de la segunda mitad del siglo XIX, cifrado en una serie de fenómenos específicos, entre los que cabría destacar la articulación de una renovada identidad gallega, traducida fundamentalmente en términos filológicos, es decir, lingüisticos; y el reconocimiento de que la producción impresa en gallego era un signo inequívoco del grado de vitalidad de esta identidad y de la correspondiente conciencia regionalista ${ }^{24}$. El "Diccionario", con mayúscula como lo escriben varios galleguistas para referirse al corpus lexicográfico ideal, necesariamente tenía que adquirir en este contexto la condición de instrumento ideal, tanto para la articulación de una conciencia colectiva, como para la salvaguarda de una lengua a punto de desaparecer o con serias deficiencias en sus manifestaciones, sobre todo en su transcripción impresa.

Del repertorio de manifiestos y opiniones aquí citados se puede deducir cómo se fue construyendo la imagen social del "Diccionario gallego", entendido como depositario de un corpus lexemático, pero sobre todo como representación de un movimiento cultural que luchaba por dotar a este idioma de los índices de vitalidad propios de una lengua institucionalizada, y por tanto normalizada. En esto, como en tantos otros aspectos de la España de la época, Galicia no era diferente de otros ámbitos socioculturales (Catalunya y Euskadi) donde circulaban reivindicaciones muy semejantes y en los que el "Diccionario" se había erigido también en texto emblemático de una identidad colectiva, interpretada desde una perspectiva regionalista e incluso protonacionalista.

\footnotetext{
${ }^{24} \mathrm{El}$ papel del mundo editorial en gallego no debe ser limitado aquí a la función de la letra impresa como denominador común de un imaginario nacional, según la archifamosa y sugerente propuesta de B. Anderson en Imagined Communities (1983). Su impronta hay que relacionarla, más bien, con la condición del libro (y de la publicación periódica) como formas culturales con capacidad para generar legitimación social y canonización simbólica. La asignación de texto fundacional de la cultura gallega moderna (y no sólo la literaria) a Cantares gallegos de Rosalía de Castro debe ser analizada en este contexto. En otras palabras, el mundo editorial adquiere en la segunda mitad del siglo XIX en Galicia una visibilidad directamente relacionada con la imperiosa necesidad de concederle "vida impresa" (pública) a la lengua y a la cultura en ella expresadas.
} 


\section{BIBLIOGRAFÍA CITADA}

Álvarez InSÚA, WaLdo. 1883. Juicio crítico a 'Aires da miña terra' de M. Curros Enríquez. La Habana: Ed. Miguel de Villa.

Cuveiro PiÑol, JuAn. 1868. El habla gallega. Pontevedra: Imprenta Antúnez.

—. 1876. Diccionario gallego. Barcelona: Tipografía de N. Ramírez.

Canalejas, Francisco De Paula. 1870. "Las leyes que presiden la lenta y constante sucesión de los idiomas en la historia indo-europea". Discurso de recepción en la RAE. En Memorias de la Academia Española, Año I, tomo II. Madrid: Impr. y Estereotipia de M. Rivadeneyra.

DeMaría, Robert JR. 1989. "The Politics of Johnson's Dictionary". PMLA 104 (1): 6474.

Dubois, Jean y Claude Dubois. 1971. Introduction à la lexicographie. Le dictionnaire. París: Librairie Larousse.

FANDIÑO, ANTONIO B. 2000 [1849]. A casamenteira. Introducción de X. R. Barreiro, Laura Tato y Carmen Blanco. Ourense: Linteo.

Hermida, CARME. 1987. "A polémica ortográfica a finais do século XIX (1888). A grafía do [s]". Grial 97: 299-316.

- 1992a. Os precursores da normalización. Defensa e reivindicación da lingua galega no Rexurdimento (1840-1891). Vigo: Xerais de Galicia.

- 1992b. A reivindicación da lingua galega no rexurdimento (1840-1891). Escolma de textos. Santiago de Compostela: Consello da Cultura Galega.

Iglesia y GonZÁlez, ANTONIO DE la. 1863. "Prólogo del Director de la Galicia, Editora de este diccionario", en Francisco J. Rodríguez, Diccionario gallego-castellano. Coruña: Imp. del Hospicio Provincial.

Lamas Carvajal, Valentín. 1998. Poesía galega. Edición crítica e Introdución de M. P. García Negro. Sada, A Coruña: Ediciós do Castro.

MARTÍNEZ PADÍN, LEOPOLDO. 1849. Historia política, religiosa y descriptiva de Galicia. Madrid: Establecimiento tipográfico de A. Vicente.

MIRÁs, FRANCISCO. 1864. Compendio de gramática gallega-castellana, con un vocabulario de nombres $y$ verbos gallegos y su correspondencia castellana. Santiago de Compostela: Mirás.

MontenEgro, Amador. 1890. "A certo... amigo". A monteira: 58, 8 de noviembre de 1890.

MOURELle-Lema, MANUEl. 1968. La teoría lingüística en la España del siglo XIX. Madrid: Editorial Prensa Española.

Murguía, Manuel. 1865. Historia de Galicia. Lugo: Imprenta de Soto Freire. Vol. I.

- 1905. "Diccionario de la lengua gallega. Necesidad de su formación y publicación". Galicia 14: 1. La Habana, 2 de abril de 1905.

Müller, MAX. 1944. La ciencia del lenguaje. Trad. de José de Caso. Buenos Aires: Ed. Albatros.

Pardo BazÁn, Emilia. 1880. [Reseña de] "Saudades gallegas". Revista de Galicia 11, 10 de junio de 1880 .

Pintos, JuAn M. 1853. A gaita gallega. Pontevedra: Imprenta de José y Primitivo Vilas.

—. 2000 [1854]. Vocabulario gallego-castellano. Edición de Marga Neira y Xesús Riveiro. Cadernos da lingua, Anexo 5. A Coruña: Real Academia Galega.

RodrígueZ, Francisco Javier. 1863. Diccionario gallego-castellano, edición de Antonio de la Iglesia. A Coruna: Imprenta del Hospicio provincial. 
SACO Y ARCE, JUAN. 1868. Gramática gallega. Lugo: Imprenta de Soto y Freire.

SARMIENTO, MARTín. 1998. Onomástico etimológico de la lengua gallega. Edición y estudio por J. L. Pensado. [A Coruña]: Fundación Pedro Barrié de la Maza.

SEOANE SÁNCHEZ, ISABEL. 1999. "O primeiro diccionario da Real Academia Galega". Cadernos da Lingua. Real Academia Galega 19: 65-84.

SOBREIRA, JUAN. 1974. "Idea de un diccionario de la lengua gallega", en Opúsculos lingüísticos gallegos del siglo XVII. Edición y estudio de J. L. Pensado. Vigo: Galaxia. VAlladARES, MARCIAL. 1884. Diccionario gallego-castellano. Santiago de Compostela: Imprenta del Seminario Conciliar Central.

Zgusta, Ladislav. 1989. "The Role of Dictionaries in the Genesis and Development of the Standard", en F. J. Hausmann et al. (eds.), Dictionaries. An International Encyclopedia of Lexicograpby. Vol. 5. 1: 70-79. Nueva York: Walter de Gruyter. 